\title{
USE OF ARTIFICIAL INTELLIGENCE METHODS IN OPERATIONAL PLANNING OF TEXTILE PRODUCTION
}

\author{
Nuritdin Yuldoshev ${ }^{1}$, Bobir Tursunov ${ }^{2}$, Saidmuhtor Qozoqov ${ }^{3}$ \\ ${ }^{1,2}$ Department of Management, Tashkent State University \\ University of Economics, Uzbekistan \\ ${ }^{3}$ Namangan Engineering Technology Institute, Namangan, Uzbekistan \\ yuldoshev51@inbox.ru, tursunov-bobir@mail.ru
}

\section{Original Scientific Paper doi:10.5937/jouproman6-17221}

\begin{abstract}
In this article, the authors analyzed the widely used methods of artificial intelligence in world practice, described the production management system. Also, the main functions are considered and it is determined that the organization of any production begins with its operational planning. And in the basis of production planning functions are various methods and algorithms of artificial intelligence. The authors considered important stages in the construction of the neural network system in planning, and discussed the most common methods and algorithms of artificial intelligence for planning textile production: taboo search method, ant algorithm, genetic algorithms, neural networks.
\end{abstract}

Keywords: textile enterprises, artificial intelligence, production planning, production management system, genetic algorithms, ant algorithm, neural networks.

\section{Introduction}

Light industry, and especially one of its leading industries - the textile industry, since the times of the industrial revolution plays an important role in the economic development of any industrial country and the expansion of the international one. It is a strategic sector for the economy of Uzbekistan, which provides a high level of employment, a contribution to the economic and industrial international authority of the country.(Tursunov B.,2017)

It should be noted that the widespread development of artificial intelligence technologies is currently associated with the fourth industrial revolution, which affects the world economy as a whole, including the textile industry. Textile enterprises are actively introducing information systems aimed at improving production efficiency. With the help of new production technologies, you can calculate, for example, deviations from the standard of material costs or the total amount of raw materials consumed. Also large textile enterprises implement ERP-systems designed to automate the management of production and financial flows, stockpiles and obtain information about their dynamics with varying degrees of coverage and depth of penetration. They allow significantly speed up data collection and analysis, assessment of potential risks, decisionmaking, while reducing the number of personnel.

\section{Literature Review}

Features of designing MES and ERPsystems in mining enterprises have been studied in scientific works Burmistrov $\mathrm{KV}$, Tsuprik LS, Burmistrova IS, Oshurkov VA (2014) Issues of technical energy accounting and process control of multi-nomenclature machine-building production were examined by researchers Mayorova ES, Oshurkov VA, Buber MG. (2015) Chusavitina GN, Makashova V.N. (2010), BarskyA.B. (2007)and others in the monograph profoundly expressed the problems of increasing the competitiveness of graduates of IT specialties of the university in the conditions of a single-industry city. 
Fuzzy systems toolbox was researched by Zadeh L.A. (1978), Beale, H. \& Demuth, H.B. (2001), Castellano, G. \&Fanelli, A.M. (2000), El-Shafie, A., Taha, M.R. \&Noureldin, A.. (2007), Lohani, A., Goel, N. \& Bhatia, K. (2006)). Possibility distribution of fuzzy decision variables obtained from possibilistic linear programming problems was founded by Tanaka H., Guo P., Zimmermann H.J. (2000 ). To problems of forecasting and modeling fuzzy multi-period production planning were devoted research works of Ying, L.C. \& Pan, M.C. (2008, )Yan-FeiLan, Yan-Kui Liu, Gao-Ji Sun. (2009), Zheng, F. \&Zhong, S.(2011, DoroninV.Yu., VolshchukovYu.N., Makashov PL, Romanenko AV, Ishmetev EN, Lednov AV, Makashova V.N. (2011).

The review of study of many economists specifies that meaning of managementof increasing capacities of textile enterprises under the conditions of modernization andeconomy diversification are studied deeply enough..(Tursunov B.,2017)

\section{Thestatementofbasicmaterials}

The rapid growth of competition in the production enterprises market, due to the economic situation and high demands of customers, increasingly makes management reconsider previous approaches to production management. In order to maintain its position in the market, to produce high quality products and at the same time to be stable in profit, any modern industrial enterprise should pay attention to optimization and automation of the technological process. This concerns both modernization of equipment, training of personnel, and introduction of new efficient production management technologies (Oshurkov V.A., and others, 2015). The main criterion for the effective operation of any enterprise is the achievement of planned targets with minimum costs. In this case, only an effective production process is clearly not enough, since the production part is closely connected with the system of sales, supply, storage, design and technological data. As an example, a production can be given on which automated systems are responsible for managing: the process (SCADA), production management (MES), enterprise performance management (ERP) systems and CAD process automation. Recently, under effective production management technologies, MES class systems refer to integrating the technological and business levels of enterprise management into a single information complex, while solving many of the most important tasks for an industrial enterprise. However, the maximum effect from the use of all the automated systems present in the enterprise can be obtained only when creating a single information space (UIS), through which all of the listed systems can exchange information in a timely and timely manner. It is difficult to imagine effective automation of the production process without considering the provision of materials and components, the work of a warehouse and many other business processes that are inextricably linked. MES - an automated system for managing and optimizing production activities, which in real time: initiates; tracks; optimizes; documents all production processes from the beginning of the order execution to the final product output (definition according to the ISA-95 standard). According to the international standard ISA-95 MES-system consists of the following functions, listed below. A schematic representation of the functions of the MES system is shown in Figure 1. Status monitoring and resource allocation (RAS (ResourceAllocationandStatus)). Managing the resources of technological equipment, raw materials, personnel, as well as other facilities necessary for conducting production activities. Provides a detailed history of resources and ensures the availability of equipment to work. It monitors the status of resources in real time. 
Resource management includes redundancy and dispatch, in order to achieve the goals of operational planning. Operational / Detailed Planning (ODS (Operations / DetailScheduling)). Ensures the ordering of production tasks, based on the order, attributes, characteristics associated with the product route maps and production technology. Forms a production schedule with minimal equipment reconfigurations and parallel operation of production facilities to reduce the time of receipt of the finished product and downtime.

Document management (DOC (DocumentControl)). Controls the content and passage of documents accompanying the products, including instructions and standards of work, methods of implementation, recipes, procedures for standard operations, programs for processing raw materials, recording production batches, reports on technical changes, transferring information from shift to shift, and provides the opportunity to lead planned and reporting production documentation. It also includes safety instructions, environmental protection controls, government and required international standards. Keeps the history of passing and changing documents. Dispatching production (DPU (DispatchingProductionUnits). Manages the flow of raw materials in the form of tasks, lots. Dispatch information is presented in the order in which the work is to be performed and changes in real time as events occur on the production line. Allows you to change the specified schedule at the production line level. Includes functions to eliminate waste and recycle waste. Collection and storage of data (DCA (DataCollection / Acquisition)). Interaction of information subsystems ERP, MES, WMS-levels in order to obtain, accumulate and transfer technological and control data circulating in the enterprise production environment. The function provides an interface for obtaining data and parameters of technological operations that are used in forms and documents attached to a product unit. 


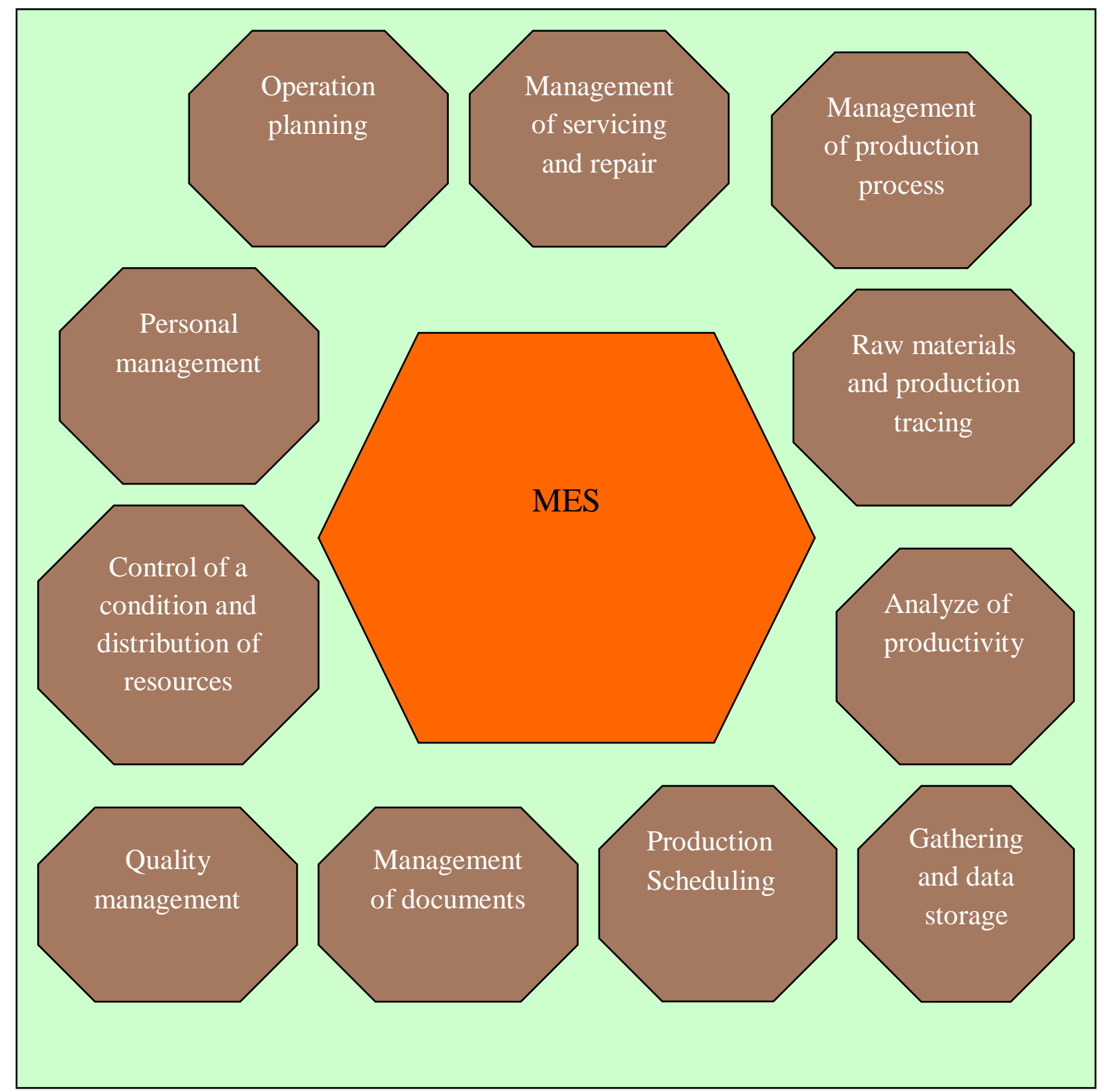

Figure 2. MES-system subsystems according to standard ISA-95.

Source: ANSI/ISA-95.00.01-2000, Enterprise-ControlSystemIntegration.

Personnel Management (LM (LaborManagement)). Provides information on the state of personnel and management in the required time frame. Includes reporting on presence and working time, certification tracking, the ability to track nonmanufacturing activities, such as material preparation or instrumental work, as a basis for costing by activity. Possible interaction with the resource allocation function, for the formation of optimal tasks. Quality management (QM (QualityManagement)). Provides real-time analysis of measured values obtained from production to ensure correct management of product quality and identify problems that require intervention by maintenance personnel. Forms recommendations for the elimination of problems, determines the causes of marriage by analyzing the relationship of symptoms, the actions of personnel and the results of these actions. Manages the implementation of laboratory studies of product parameters. Management of production processes (PM (ProcessManagement)). 
It monitors the production process and either adjusts automatically or provides support for the operator's decision-making to perform corrective actions and improve production activities. This activity can be both intra-operational and directed solely at the monitored and managed equipment, and interoperational, tracking the progress of the process from one operation to another. Includes alarm management to ensure that personnel are notified of changes in the process that go beyond acceptable limits of sustainability. Maintenance and repair management (MM (Maintenance Management)). Tracks and manages the maintenance of equipment and tools. Ensures their operability. Provides scheduling of periodic and preventive repairs, repair of the state. Accumulates and stores the history of events that occurred (failure, loss of productivity, etc.) for use in diagnosing problems that arose and preventing possible problems. Tracking of raw materials / products (PTG (ProductTrackingandGenealogy)). Provides the abi lity to obtain information about the status and location of the lot at any given time. The status information may include data on who performs the task, the raw materials and their suppliers, the current production conditions, as well as any alarms, re-treatment data and other events related to the product. Performance analysis (PA (PerformanceAnalysis)). Provides the formation of reports on the actual results of production activities, comparing them with historical data and the expected commercial result. The results of production activities include indicators such as resource utilization, resource availability, cycle time per unit of output, compliance with the plan and compliance with performance standards. Systematizes information obtained from various functions that measure production parameters. These results can be prepared in the form of a report or presented in real time in the form of a current performance assessment. Any production begins with planning. Let's consider in more detail the planning functions in MES-systems: Planning of output in accordance with sales plans, projects, orders. Formation of production plans of workshops throughout the entire technological chain of product creation. Planning needs in materials, raw materials, components, labor, 135 equipment. Calculation of planned costs for production and its profitability. Accounting for the actual costs of production and the calculation of its actual cost. Plan / fact analysis of the production activity of the enterprise. To implement the allocated production planning functions, different types of artificial intelligence are used in MES-systems. Let us consider them in more detail. Artificial intelligence in planning When planning production, artificial intelligence allows you to predict at some generalized level, for example, at the level of a group of nomenclature and then divide the generalized forecast to a single level using additional calculations.

Taboo search is a variant of the method of gradient descent with memory. During the search, a list of taboo items (prohibited for transition) from the number already calculated is maintained. Critical parameters of the algorithm is the range of prohibitions. During the search, the operations of including in the forbidden list of states around the current state are performed, which adds the randomness factor to the search process. The process of readjustment occupies an important place in the planning system, since it occupies a significant part of the total calendar time (from several hours to the whole shift). The more recalibration is required (by production conditions), the more time is lost. Therefore, one of the main tasks is the improvement of the equipment changeover systems, as well as the use of methods that allow to obtain the optimal sequence of machining of parts on machine tools with minimal time loss for readjustment. 
In order to reduce the waiting time for processing for all parts or parts of the order, downtime of equipment, and also to reduce the time of the entire production cycle of the order fulfillment, the solution of the task of optimizing the production process can be performed in accordance with the following criteria:

1. Minimization of waiting time for maintenance, i.e., ensuring a complete release of parts, improving the structure of the unit-calculation time:

$$
K_{1}=\min \left(\sum_{i \in I_{s}} W_{i j}\right),
$$

1. Here $W_{i j}$ - the time interval between the end (j-1) -th and the beginning of the $\mathrm{j}$-th operation of the i-th part;

$I_{s^{-}}$set of order details "s".

2. Minimize equipment down time (maximumload):

3. $K_{2}=\min \left(q_{i k}-\sum_{i \in I_{s}} F_{i k s}\right)$,

Here

$q_{i k^{-}}$the complexity of the operation of thei-thpartonthek-thmachine, $F_{1}=\left(W_{i j}+p_{i}\right)-$ duration of

passage of the i-th part in the system, including idle time;

$p_{i}=\sum_{j \in G_{i}} p_{i j^{-}} \quad$ total duration

of all operations of the i-th part;

$p_{i j j^{-}}$duration of the operation;

$G_{i^{-}}$the set of operations of the i-th part.

Minimizing the execution time of all work on the set of parts:

$$
K_{3}=\min \left(\sum_{i \in I_{s}} R_{i k}-\sum_{i \in I_{s}} F_{i}\right)
$$

here

$R_{i k^{-}}$the amount of work to be done on the ith order detail "s".
The essence of operational-calendar planning reflects the criterion of optimality minimization of the duration of the plan or the total waiting time for servicing of parts (products). Thus, the search for an optimal plan is to minimize not so much equipment downtime, as long as the parts are waiting for processing. Minimizing the waiting time is ensured by calculating the processing time of all parts, in which the duration of technological operations is best synchronized and the equipment load is increased. In a single production there are frequent downtime due to the complexity of operational management, which includes the construction of calendar plans for short periods of time (week, day, shift). When developing plans, it is necessary to take into account the state of all elements of the production system: the operability of the equipment, the availability of materials, the availability of the necessary tools.Many real production tasks are formulated as the search for the optimal value, where the value is a complex function, depending on many input parameters. Optimization of multiparameter functions is the most popular application of genetic algorithms. When forming the schedule, some parameters have a random character, which affects the course of production and the execution of the plan. The schedule is an idealization of the technological process. In real conditions, there are deviations, which can be associated with the breakdown of equipment or tools, the lack of raw materials in warehouses, the marriage of any part. There is a need to make changes to the schedule. Therefore, the quality of the scheduling created during the rescheduling process depends on what data can be entered into the system within the control of deviations and how long this will take. Replanning is one of the important elements of keeping the schedule up to date.The use of evolutionary methods, for example, the ant algorithm, allows to solve the problem of minimizing readjustment and downtime of equipment with a large number of machines. 
The process of readjustment occupies an important place in the planning system, since it occupies a significant part of the total calendar time (from several hours to the whole shift). The more recalibration is required (by production conditions), the more time is lost. Therefore, one of the main tasks is the improvement of the equipment changeover systems, as well as the use of methods that allow to obtain the optimal sequence of machining of parts on machine tools with minimal time loss for readjustment.Compared to other methods, this algorithm gives the best solution, but it takes more time to calculate than, for example, taboo search, which finds a good solution (but not optimal) five times faster. The use of a genetic algorithm to solve the problem of the distribution of orders for machines and their uniform loading makes it possible to obtain a solution that is almost the same as the ant algorithm. At the same time, the search time for the solution is $15 \%$ less, the result is no more than $2 \%$. For small volumes, problems yield the same results. Comparing the ant algorithm with the exact methods, for example dynamic programming or the method of branches and boundaries, we can say that it finds solutions close to optimal in a much shorter time even for problems of small dimension. The optimization algorithms described above for the production of detailed production schedules belong to the class of APSsystems (Advanced Planning and Scheduling), relatively to the young direction of corporate information systems. Being tools for simulation of production activities, APS-systems are used to support decision-making in the operational management of an enterprise(Beale, H. \& Demuth, H.B. (2001).)

The ant algorithm allows you to find the optimal production route for a given constraint. In the conducted study of the process of finding the optimal route by the ant algorithm, data were obtained on which of the 100 iterations, the "ants" found the optimal routes three times. Carried out computer experiments show that the ant algorithms find good routes much faster than the exact methods of combinatorial optimization. The effectiveness of ant algorithms increases with the increase in the dimension of the optimization problem.

Genetic algorithms. If we take as a basis a modified genetic algorithm, then the effectiveness of the application of genetic algorithms depends on how expedient the coding of the solution is. As genetic operators are used: selection; reproductions; crossing-over; mutations; migration. Traditionally, specific limitations in the search optimization problem were laid in the form of penalty functions, which were taken into account when calculating the value of the objective function (fitness function) of the corresponding individual. The imposition of a certain "fine" on an individual means a decrease in the value of its objective function in the event that the solution that is a particular individual goes beyond the boundaries of the region of admissible solutions. Thus, all the specificity of the optimization problem being solved was taken into account in the unit for calculating the fitness function of the individual, and, as a consequence, in the reproduction operator. The quality of the development of penalty functions, namely the sensitivity of the algorithm to changes, directly affects the rate of convergence and obtaining a solution that satisfies the constraints. In addition to the use of penalty functions, it is proposed to modify the logic of the basic operators of genetic search. The idea of modification is reduced to the application of rules that guide experts in the subject area when building a schedule. The essence of these rules consists in the directed adjustment of individual parameters of production tasks with the purpose of resolving collisions that arise when constraints are violated due to the specific nature of the problem. Modification involves changing the basic operators of mutation and crossover. 
In particular, for the crossover operator, a special rule 137 for selecting alleles is applied when crossing chromosomes. To visualize the modified logic, a simplified example is presented, within the framework of which 5 works are considered, 3 alternative production lines. Two chromosomes were selected, representing different solutions, namely, assignment options and the sequence of work performed by production lines. Each rectangle is marked with an index of the corresponding work. Rectangles are arranged horizontally along the lines defining a particular production line. Thus, we get a variation of the Gantt chart, often used to visualize schedules. For each production line, pairs of jobs are formed, one from each individual. For each pair, we randomly determine the future belonging to the corresponding descendant. This checks for duplication of work in the same solution. Result of crossing - new solutions are obtained, obviously excluding violations of certain restrictions. Thus, the predecessor factor is added to the logic of the basic genetic operator, excluding potential solutions, that is, descendants that obviously do not satisfy the constraints.

Neural networks. The neural network is a system of connected and interacting simple processors (neurons). The structural scheme of the neural network is shown in Figure 2, where the green color is the input layer of the neurons, the blue is the hidden (intermediate) layer of the neurons, the yellow is the output layer of the neurons. The neuron is the basic element of a neural network, a single simple computing processor capable of perceiving, converting and distributing signals, in turn combining a large number of neurons into one network allows solving rather complicated tasks. Neural networks are a very powerful and flexible mechanism for planning and forecasting. When determining what needs to be planned, it is necessary to specify variables that are analyzed and predicted. Here the required level of detail is very important. Many factors influence the level of detail used: the availability and accuracy of the data, the cost of analysis, and the preferences of the users of the planning results. In situations where the best set of variables is unclear, you can try different alternatives and choose one of the options that gives the best results. Usually this is the choice in the development of planning systems based on the analysis of historical data.The second important step in building a neural network planning system is the definition of the following three parameters: the planning period, the planning horizon and the planning interval. 


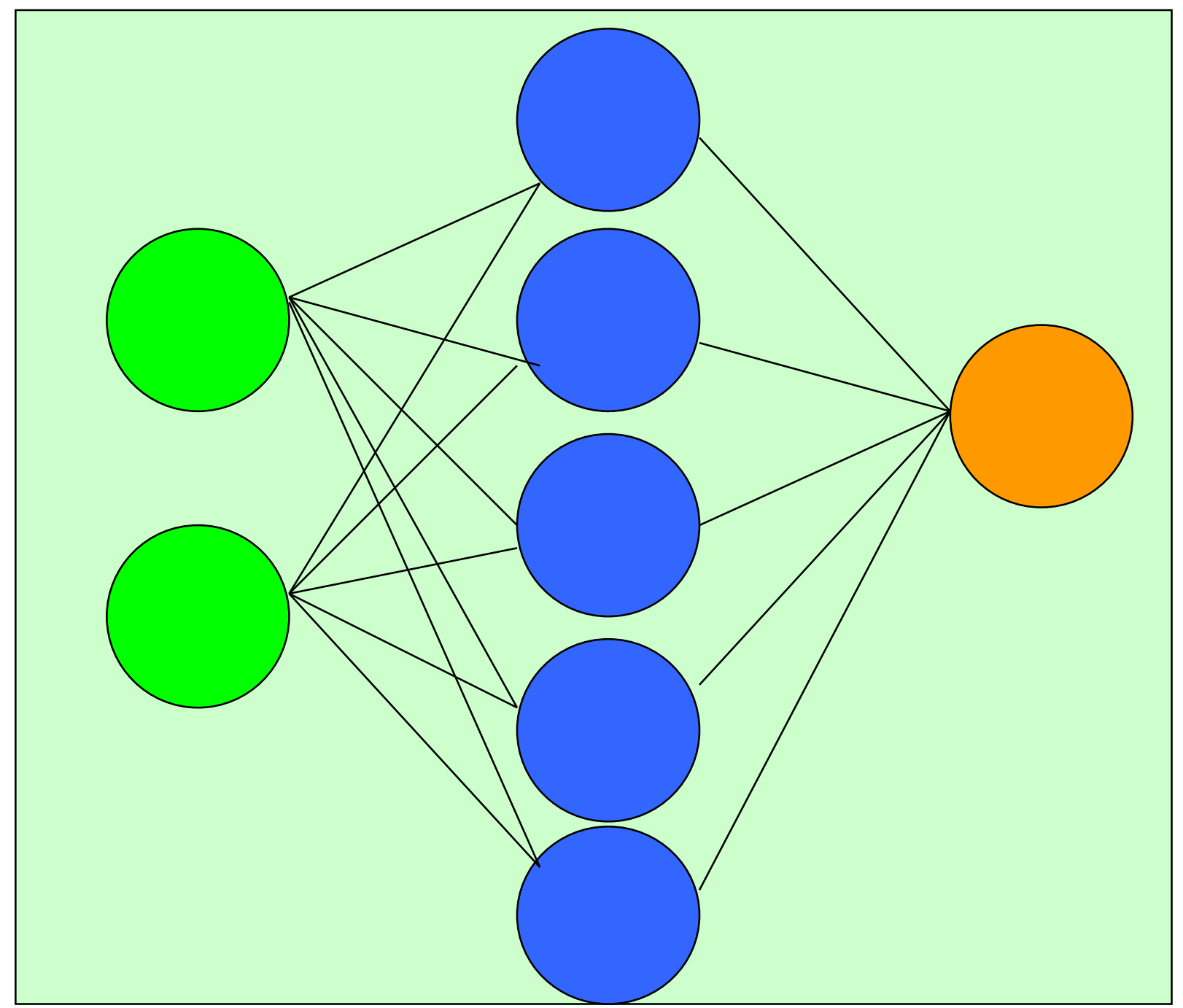

Figure 2. Structural diagram of the neural network.

Source: ANSI/ISA-95.00.01-2000, Enterprise-ControlSystemIntegration.

The planning period is the basic unit of time for which a forecast is made. The planning horizon is the number of periods in the future that covers the forecast. That is, you may need a forecast for 10 days ahead, with data for each day. In this case, the period is a day, and the horizon is 10 days. Finally, the planning interval is the frequency with which a new forecast is made. Often, the planning interval is the same as the planning period. The choice of period and planning horizon is usually dictated by the decision conditions in the area for which the forecast is made. The choice of these two parameters is almost the most difficult in neural network planning. In order for planning to make sense, the planning horizon must be no less than the time needed to implement the decision taken on the basis of the forecast. Thus, planning depends very much on the nature of the decision. In some cases, the time required to implement the solution is not defined, for example, as in the case of the supply of spare parts for the replenishment of repair shops. There are methods of working in conditions of this uncertainty, but they increase the variation of the planning error. Since the accuracy of the forecast usually decreases with the increase in the planning horizon, it is often possible to improve the decision-making process, reducing the time needed to implement the solution and, therefore, reducing the horizon and planning error. 
In some cases, it is not so important to predict specific values of the planned variable, as predicting significant changes in its behavior. This problem arises, for example, in predicting the moment when the current direction of the market movement will change its direction to the opposite.

\section{Conclusions}

Artificial intelligence is one of the directions of computer science, the purpose of which is the development of computer systems capable of performing functions traditionally considered to be intellectual understanding of language, logical inference, use of accumulated knowledge, training, planning of actions and so on. The main areas of research in the field of artificial intelligence are the proof of theorems, training and the identification of regularities, communication in natural language, pattern recognition, computer vision.

According to LutfiZadeh, the human way of reasoning, based on natural language, can not be described in the framework of traditional mathematical formalisms. These formalisms are characterized by strict unambiguous interpretation, and everything that is associated with the use of natural language, has a multivalued interpretation. From the very beginning, the main pragmatic goal of LutfiZadeh is the creation of an apparatus capable of simulating human reasoning and explaining human decision-making techniques in the course of solving various problems. The ideas of LutfiZadeh and his followers are used in creating systems that understand texts in natural language, when creating planning systems based on incomplete information, processing visual signals, managing technical, social and economic systems, in artificial intelligence systems and robotic systems. (Zadeh L.A. (1978))
The application of artificial intelligence methods and algorithms extends the capabilities of planning systems in the context of the formalization of expert rules that allow to take into account the specifics of technological and production processes. Artificial intelligence will significantly improve the operational planning system, thereby reducing the time to obtain optimal or acceptable production schedules. If there are random events affecting the production process, it will allow you to react quickly to changes and corrections in the original data. It is also possible to combine methods and algorithms of artificial planning in the implementation of planning functions in production management systems.

\section{References}

1. Barsky A.B. (2007) "Logical neural networks" Moscow: Internet-University of Information Technologies.

2. Beale, H. \& Demuth, H.B. (2001). Fuzzy systems toolbox for use with MATLAB, 1st ed., Massachusetts: International Thomson Publishing.

3. Burmistrov K.V., Tsuprik L.S., Burmistrova I.S., Oshurkov V.A. Osobennost i proyektirovaniya mesierp-sistem na gorno dobyvayushchikh predpriyatiyakh //NauchnyyetrudySWorld. 2014. T. 9. № 4. pp. 94-99.

4. Castellano, G. \& Fanelli, A.M. (2000). Variable selection using neural-network models, Neurocomputing, 31, pp 1-13.

5. Chusavitina G.N., Makashova V.N. i dr. Povysheniye konkurentosposobnostivy pusknikov IT-spetsial'nostey vuza v usloviyakh monopromyshlennogo goroda. Monografiya. Pod red. G.N. Chusavitinoy. Magnitogorsk: MaGU, 2010. -158 p.

6. DoroninV.Yu., VolshchukovYu.N., Makashov PL, Romanenko AV, Ishmetev EN, Lednov AV, Makashova V.N. (2011) Building a system for dispatching and controlling technological processes as an element of industrial enterprise management. // Management of large systems. Moscow, pp. 116-119.

7. El-Shafie, A., Taha, M.R. \&Noureldin, A.. (2007). A neuro-fuzzy model for inflow forecasting of the Nile River at Aswan High Dam, Water Resources Management, 21(3), pp 533-556. 
8. Eremenko YI, Tsukanov MA, SolovyevA.Yu. (2013) About application of multi-agent algorithms of ant colonies for the decision of a problem of structural optimization in power systems // Fundamental researches. Vol. 10-15. - pp. 3316-3320; URL: www.rae.ru/fs/?section=content\&op=show article\&article_id=10002326 (reference date: 08.10.2015).

9. Gladkov L.A., Kureichik V.V., Kureichik V.M. (2006) Genetic Algorithms: Textbook. - 2 nd ed. - M: Fizmatlit, p. 320. - ISBN 59221-0510-8.

10. MayorovaYe.S., Oshurkov V.A., Buber M.G. Kontseptsiya tekhnicheskogo i kommercheskogo energoucheta promyshlennykh predpriyatiy//Aktual'nyye problemy so vremennoy nauki, tekhnikii obrazovaniya.2015. T. 2. № 1. S. 135-138.

11. Lohani, A., Goel, N. \& Bhatia, K. (2006). Takagi-Sugeno fuzzy inference system for modeling stage-discharge relationship, Journal of Hydrology, 331, pp 146-160.

12. Oshurkov V.A., Tsuprik L.S., MayorovaYe.S., Burmistrov K.V., Burmistrova I.S. Razrabotka sistemy upravleniya tekhnologicheskim protsess ommnogonomen klaturnogo mashinostroitel'nogo proizvodstva v usloviyakh primeneniya stankov s CHPU//Mashinostroyeniye: setevoy elektronnyynauchnyyzhurnal. 2015. T. 3. № 3. S. 53-55.
13. Tanaka H., Guo P., Zimmermann H.J. (2000) Possibility distribution of fuzzy decision variables obtained from possibilistic linear programming problems, Fuzzy Sets and Systems. pp. 323_332.

14. Tursunov B. (2017) Vestnik Instituta Rossiyskoy Akademii nauk. Vol.5, 2017.Moscow. 146-156 pp.

15. Tursunov B. (2017) Role of managing industrial stocksin increasing of textile enterprises capacity.Vol.6, Number 4, Fall 2017.

16. Yan-FeiLan, Yan-Kui Liu, Gao-Ji Sun. (2009) Modeling fuzzy multi-period production planning and sourcing problem with credibility service levels. Journal of Computational and Applied Mathematics. pp 208_221.

17. Ying, L.C. \& Pan, M.C. (2008). Using adaptive network based fuzzy inference system to forecast regional electricity loads, Energy Conversion and Management, 49(2), pp 205-211.

18. Zadeh L.A. (1978) Fuzzy sets as a basis for a theory of possibility, Fuzzy Sets and Systems, Vol. 3, p 28.

19. Zheng, F. \&Zhong, S. (2011). Time series forecasting using a hybrid RBF neural network and AR model based on binomial smoothing, World Academy of Science, Engineering and Technology, 75, pp 14711475.

20. ANSI/ISA-95.00.01-2000, EnterpriseControl System Integration. 